\title{
Nada é certo, mas escreva: três poemas de Franco Fortini em tradução
}

Clándia Tavares Alves'

Resumo: Serão apresentadas, neste artigo, traduções de três poemas de Franco Fortini, acompanhadas de uma breve introdução e análise. Os textos selecionados - "Forse il tempo del sangue ritornerà...", "Traducendo Brecht" e "La gioia avvenire" - remetem a um contexto de intensa atividade intelectual e cultural na Itália, do qual Fortini fez parte enquanto um importante pensador dos rumos do país após o fim do fascismo.

Palavras-chave: Franco Fortini; Tradução de Poesia; Literatura Italiana.

\section{Introdução}

Franco Fortini (Florença, Itália, 1917 - Milão, Itália, 1994) foi um dos grandes intelectuais do Novecento italiano. Poeta, crítico literário, ensaísta, tradutor e professor universitário, vivenciou quase todo o século em que se deram as principais transformações ocorridas na Itália antes, durante e depois do fascismo e da Segunda Guerra Mundial. Seu olhar atento à sociedade em transformação, atrelado a um rigor ideológico latente e uma apurada capacidade criativa, fizeram-no um grande poeta e intelectual, de forma que essas duas facetas se complementaram ao longo de toda a sua obra. Entre os livros de poesia que publicou, destacam-se Foglio di via e altri versi (1946; 1967), Poesia ed errore (1959) e Composita solvantur (1994).

1 Professora Substituta do Departamento de Língua e Literatura Estrangeiras - Letras Italiano da Universidade Federal de Santa Catarina. Doutora em Teoria e História Literária pela Universidade Estadual de Campinas. E-mail:< clautalves@gmail.com>. 
Dentre os ensaios, sua atuação enquanto crítico literário e pensador da sociedade italiana se destacou em Verifica delpotere (1965), obra que ocupa lugar central entre as reflexões que se dedicaram a pensar as primeiras décadas após o fim da guerra na Itália. Fortini também contribuiu intensamente com vários periódicos, dentre eles, a revista Il Politecnico, ao lado de Elio Vittorini. Publicou ainda o volume Attraverso Pasolini (1993), no qual revisita as principais convergências e divergências que compartilhou com o amigo-inimigo.

Os poemas reunidos e traduzidos nesta pequena seleção são provenientes de publicações diversas. "Forse il tempo del sangue ritornerà..."” saiu na seção "1958" de L'ospite ingrato (1966), livro que escapa a definições ao reunir escritos de diferentes gêneros textuais, caminhando entre prosas e poesias ensaísticas. "Traducendo Brecht" sempre (1963) e compõe a seção “Traducendo Brecht I (1959-1961)”. Finalmente, "La gioia avvenire" foi publicado na segunda edição revista, de 1967, do primeiro livro de poemas de Fortini, Foglio di via e altri versi, cuja primeira publicação se deu em 1946. Ali, tematizam-se, sobretudo, questões referentes à experiência da guerra - e, nesse sentido, o acréscimo de "La gioia avvenire" à edição revisada posteriormente pode representar uma espécie de desejo do poeta por uma nova conclusão à experiência traumática relatada anteriormente. Todos os três poemas foram, portanto, escritos durante a década de 1960, momento em que a euforia revolucionária de reinventar o país com base em novos valores, após o fim do fascismo, passa a ser sutilmente sobreposta à necessidade de encontrar um outro lugar simbólico em que literatura e política pudessem se integrar ao projeto de uma nova sociedade.

\section{Notas sobre os poemas e as traduções}

Partindo desse recorte histórico e cronológico, a ideia de agrupar e traduzir tais poemas surgiu da constatação de que os três textos tratam, em alguma medida, de uma mesma temática fundamental: a urgência de se manter em movimento

2 Uma versão preliminar de "Talvez o tempo do sangue voltará...” foi publicada na página do blog Marca Páginas, em fevereiro de 2019 (disponível em: < https://www.facebook.com/blogmarcapaginas/ posts/1232088323636538>; acesso em 30 de junho de 2020).

3 Uma versão preliminar de "Traduzindo Brecht" foi publicada no blog Ponto Virgulina, em novembro de 2018 (disponível em: < https://traducaoliteraria.wordpress.com/2018/11/08/traduzindo-brecht-de-franco-fortini-traducao-claudia-alves / > ; acesso em 30 de junho de 2020). 
mesmo diante das calamidades eminentes. Ou seja, apesar de serem poemas que passam grande parte de sua extensão descrevendo imagens de impacto, observadas segundo uma chave negativa dos acontecimentos (o sangue, o temporal, o grito), reverte-se o sinal dessa representação quando, ao terminar a leitura, somos tomadas e tomados por verbos que nos impelem à ação: mudar, escrever, brilhar.

O reconhecimento dessa ambivalência de sinais, que reverte a potência da poesia ao final da leitura, foi, portanto, o grande fio norteador dessas traduções. Por isso, optei por priorizar, na medida do possível, as imagens criadas pelos poemas, mais do que a tradução precisa de determinados termos. Além disso, tentei recriar em português um certo estranhamento das estruturas sintáticas que existe na língua italiana; por exemplo, no verso final de "La gioia avvenire" - "Come le siepi del marzo brillano le veritä" - no qual invertem-se os elementos da oração e deixa-se o sujeito de "brilham", isto é, "as verdades", no final do verso, a fim de criar a rima com "as eternidades" do verso anterior.

É preciso notar também as bem-sucedidas tentativas de transferir as rimas, assonâncias e aliterações do italiano para o português devido à similaridade compartilhada entre as duas línguas - por exemplo, nos versos que terminam em -dades, como já vimos em "eternidades" e "verdades", ou ainda nos verbos "ver" e "perder". Porém, nem sempre esse procedimento de transferência deu certo. Em "Traducendo Brecht”, por exemplo, o paralelo criado pela repetição dos termos "oppressi" e "tranquilli" não pode ser mantido em português. Por outro lado, vale ainda notar os casos em que adaptações foram feitas, como no caso dos verbos "oltrepassare" e "fare", que foram levemente adaptados para os verbos "transcender" e "fazer", em "Talvez o tempo do sangue voltará...", com $\mathrm{o}$ intuito de recriar a rima.

A escolha de priorizar as imagens e as temáticas se sustentaria pelo fato de a poesia de Fortini, assim como a sua obra crítica, ser perpassada por um forte elemento político, de forma que a literatura e a atuação intelectual se complementam de maneira quase simbiótica em seus escritos. Nesse sentido, o engajamento do poeta e ensaísta orienta o uso que ele faz das palavras, algo que, acredito, deveria ser mantido nas traduções. Paralelamente a esse fato, o poeta é também um sujeito histórico que presenciou a concretização de um regime totalitário, a existência de uma guerra, além da ascensão e do declínio de um sonho socialista, materializado pela experiência da União Soviética - temas que emergem desses escritos, cuja função é, também, questionar as possíveis funções de um escritor intelectual. Por isso, ciente desse lugar histórico que Fortini e seu eu-lírico assumem, a experiência de leitura das traduções deveria reproduzir nas leitoras e nos leitores brasileiros 
esse mesmo efeito de arrebatamento e renovação que a leitura em língua original nos sensibiliza.

Assim, poderíamos dizer que nesta breve amostragem da poesia de Fortini nos deparamos com uma voz poética que reconhece a emergência de estar atento ao seu próprio tempo, não ignorando as chances de o "tempo do sangue" voltar - uma ameaça que parece nos espreitar recorrentemente ao longo da história. Entretanto, mesmo ciente desse sangue e desse pranto que fazem parte dialeticamente da "escola da alegria", o poeta não poderia deixar de continuar enxergando uma "pequena porta" entreaberta, citando aqui o verso de Bertold Brecht usado como epígrafe por Fortini na seção "Traducendo Brecht I (1959-1961)". Entrando por essa pequena porta, é possível criar novas hipóteses sobre as razões que levaram Fortini a inserir o poema "La gioia avvenire" à revisão que realizou na primeira coletânea de poemas que publicou: o horror do que foi vivido durante a guerra não deveria ser mais forte do que a crença de que uma alegria, ainda, estaria por vir. Alegria parece uma palavra um pouco desajustada para ser utilizada hoje em dia, soa quase como uma distração lexical. Entretanto, reiteradamente, esses poemas repetem a improvável conclusão de que podemos, ainda, ter esperança.

\section{"Talvez o tempo do sangue voltará..."}

Talvez o tempo do sangue voltará.

Há homens que devem ser assassinados.

Pais que devem ser ridicularizados.

Lugares para profanar blasfêmias para proferir

incêndios para fitar delitos para aplaudir.

Mas ainda há o que retornar a uma outra paciência

à feroz ciência dos objetos à coerência

nos dilemas que acreditamos transcender.

Ao partido que precisa assumir e fazer.

Procurar os nossos iguais ousar reconhecê-los

deixar que nos julguem guiá-los sermos guiados

com eles querer o bem fazer com eles o mal

e o bem a realidade servir negar mudar.

4 "Ainda enxergo uma pequena porta". In: BRECHT, Bertold. Poesia. Tradução de André Vallias. Livro digital. São Paulo: Perspectiva, 2019. 
"Forse il tempo del sangue ritornerà..."

Forse il tempo del sangue ritornerà.

Uomini ci sono che debbono essere uccisi.

Padri che debbono essere derisi.

Luoghi da profanare bestemmie da proferire

incendi da fissare delitti da benedire.

Ma più c'è da tornare ad un'altra pazienza

alla feroce scienza degli oggetti alla coerenza

nei dilemmi che abbiamo creduto oltrepassare.

$\mathrm{Al}$ partito che bisogna prendere e fare.

Cercare i nostri eguali osare riconoscerli

lasciare che ci giudichino guidarli esser guidati

con loro volere il bene fare con loro il male

e il bene la realtà servire negare mutare. 


\section{Traduzindo Brecht}

Um grande temporal,

durante toda a tarde, retorceu-se

por cima dos telhados antes de se romper em relâmpagos, água.

Eu fitava versos de cimento e de vidro

onde havia gritaria e pragas muradas e membros

também meus, que sobrevivo. Com cautela, olhando

ora as telhas batalhadas, ora a página seca,

eu escutava morrer

a palavra de um poeta ou transformar-se

em outra, não mais por nós, voz. Os oprimidos

estão oprimidos e tranquilos, os opressores tranquilos

falam ao telefone, o ódio é educado, eu mesmo

acredito não saber mais de quem é a culpa.

Escreva, digo a mim mesmo, odeia

quem com doçura guia ao nada

os homens e as mulheres que contigo se fazem companhia

e acreditam não saber. Entre os inimigos

escreva também o teu nome. O temporal

dissipou-se com ênfase. A natureza

ao imitar as batalhas é bastante fraca. A poesia

não muda nada. Nada é certo, mas escreva. 


\section{Traducendo Brecht}

Un grande temporale

per tutto il pomeriggio si è attorcigliato

sui tetti prima di rompere in lampi, acqua.

Fissavo versi di cemento e di vetro

dov'erano grida e piaghe murate e membra

anche di me, cui sopravvivo. Con cautela, guardando

ora i tegoli battagliati ora la pagina secca,

ascoltavo morire

la parola d'un poeta o mutarsi

in altra, non per noi più, voce. Gli oppressi

sono oppressi e tranquilli, gli oppressori tranquilli

parlano nei telefoni, l'odio è cortese, io stesso

credo di non sapere più di chi è la colpa.

Scrivi mi dico, odia

chi con dolcezza guida al niente

gli uomini e le donne che con te si accompagnano

e credono di non sapere. Fra quelli dei nemici

scrivi anche il tuo nome. Il temporale

è sparito con enfasi. La natura

per imitare le battaglie è troppo debole. La poesia

non muta nulla. Nulla è sicuro, ma scrivi. 


\section{A alegria por vir}

Poderia ser um rio grandioso

Uma cavalgada aos trotes um tumulto um furor

Uma raiva dilacerada um cabo destroçado

Um grito altíssimo.

Mas também uma minúscula grama para os retornos

A queda de uma pinha queimada pela chama

Uma mão que encosta de passagem

Ou a indecisão fitando sem ver.

Algo portanto que não podemos perder

Mesmo que cada outra coisa esteja perdida

$\mathrm{E}$ que perpetuamente celebraremos

Pois cada coisa nasce daquela somente.

Mas antes de chegar lá

Antes a miséria profunda como a lepra

$\mathrm{E}$ as maldições enganadas e a verdadeira morte.

Você que acredita esquecer vaidoso

Ou mascarado de revolução

A escola da alegria está repleta de choro e sangue

Mas também de eternidades

E das bocas desaparecidas dos santos

Como arbustos de março brilham as verdades. 


\section{La gioia avvenire}

Potrebbe essere un fiume grandissimo

Una cavalcata di scalpiti un tumulto un furore

Una rabbia strappata uno stelo sbranato

Un urlo altissimo.

Ma anche una minuscola erba per i ritorni

Il crollo d'una pigna bruciata nella fiamma

Una mano che sfiora al passaggio

O l'indecisione fissando senza vedere.

Qualcosa comunque che non possiamo perdere

Anche se ogni altra cosa è perduta

E che perpetuamente celebreremo

Perché ogni cosa nasce da quella soltanto.

Ma prima di giungervi

Prima la miseria profonda come la lebbra

E le maledizioni imbrogliate e la vera morte.

Tu che credi dimenticare vanitoso

O mascherato di rivoluzione

La scuola della gioia è piena di pianto e sangue

Ma anche di eternità

E dalle bocche sparite dei santi

Come le siepi del marzo brillano le verità.

\section{Referências bibliográficas}

BRECHT, Bertold. Poesia. Trad. André Vallias. Livro digital. São Paulo: Perspectiva, 2019. FORTINI, Franco. La gioia avvenire. In: Tutte le poesie. Org. L. Lenzini. Livro digital. Milão: Mondadori, 2015.

FORTINI, Franco. Traducendo Brecht. In: Tutte le poesie. Org. L. Lenzini. Livro digital. Milão: Mondadori, 2015.

FORTINI, Franco. Forse il tempo del sangue ritornerà... In: . L'ospite ingrato primo e secondo. Casale Monferrato: Marietti, 1985. 